\title{
Effect of Local Vibration on Triceps Surae Flexibility Compared to Static Stretching
}

Seol Park

Department of Physical Therapy, College of Health Science, Catholic University of Daegu, Daegu, Korea

Purpose: This study examined the effects of local vibration using a massage gun on the triceps surae flexibility by measuring the ankle dorsiflexion range of motion (ROM) compared to static stretching in healthy adults.

Methods: Twenty healthy subjects were instructed in this study. They were allocated randomly to two groups: local vibration (LV) and static stretching (SS). The ankle dorsiflexion ROM was measured before and after the intervention in supine (open kinetic chain, OKC) and standing (closed kinetic chain, CKC). The LV group received local vibration using a massage gun for five minutes on their triceps surae, and the SS group stood on the $\mathrm{Q}$ board with a dorsiflexed ankle for five minutes. The ROM between pre- and post-intervention and the change in ROM between two groups were analyzed. A paired t-test was used to compare the ROM between pre- and post-intervention, while an independent t-test was used to compare the change in ROM between the two groups.

Results: Both groups showed a significant difference between pre- and post-intervention in the position of both the OKC and CKC. The change in ROM, however, was not significantly different between the two groups.

Conclusion: The application of local vibration using a massage gun for five minutes on the triceps surae could improve its flexibility as much as the application of static stretching. A massage gun for the application of a local vibration stimulus may be effective, simple, portable, and comfortable.

Keywords: Vibration, Ankle, Range of Motion, Muscle Stretching Exercise

서 론

진동 치료는 유연성-3이나 근력을 향상시키고 통증을 감소시키 는 데에 널리 사용된다. 진동 자극이 인체에 주어지면 근육 내 근방추 의 일차종말에서 자발적인 발화율이 감소되어 긴장이 감소하고, ${ }^{5}$ 이 로 인해 근육의 유연성이 증가하게 된다. ${ }^{6}$ 또한 진동으로 인해 혈류 순환이 향상되어 열 효과를 가지게 되고, ${ }^{6}$ 이는 근섬유의 진동, 피부 및 심혈관의 혈관 확장으로 인해 근육의 신장력을 촉진시킬 뿐만 아 니라 통증을 감소시킨다. 인체에 진동 치료를 적용하는 방법에는 적 용하는 부위에 따라 신체 전반에 적용하는 방법(whole body vibration, WBV)과 국소 부위에 적용하는 방법(local body vibration, LV)이 있다. $\mathrm{WBV}$ 는 주로 진동판 위에 서서 스쿼트나 바로 선 자세에서 적용되는 데, 근력 강화,89 균형,10 및 보행 속도 향상1ㅣ 등의 효과가 있다.

$\mathrm{Kurt}^{12}$ 는 WBV의 경우 진동 자극이 발을 통해 신체 조직으로 간접 전달되며, 이 자극이 전달되는 동안 진동 에너지는 연부조직에 의해
흡수되어 자극이 감소될 수 있고, 따라서 불충분한 효과를 얻을 수 있다고 하였다. 이를 극복하기 위해 진동판 위에 서거나 스쿼트 동작 을 수행하는 것 대신 무릎, 엉덩관절 등 발 외의 부위를 진동판 위에 두어 $\mathrm{LV}$ 를 적용하였는데, 이를 통해 진동판 위에서의 자세 변경으로 $\mathrm{LV}$ 를 적용할 수 있을 뿐만 아니라 WBV보다 유연성 향상에 더 효과적 임을 알 수 있다. 하지만 대부분의 WBV나 위 연구에서 $\mathrm{LV}$ 를 적용할 때 사용했던 장비의 경우 부피가 큰 고가의 장비이며, 가정에서 쉽게 적용할 수 없는 단점이 있다. 또한 Bakhtiary 등6은 LV가 WBV에 비해 쉽고 간단하며, 가격이 싸고 더 광범위하게 적용할 수 있다고 하였다.

근력 강화 향상을 위해 주로 적용하는 WVB와는 달리 LV는 특정 한 국소 부위에 진동 자극을 적용하여 유연성6,12,13을 향상시키거나 경직을 감소 ${ }^{13}$ 시키는 데에 사용된다. $\mathrm{LV}$ 를 적용하기 위해서는 위에서 언급한 장비 외에도 Theragun (Theragun, USA)과 같은 휴대용 근육 타진기(hand held percussion device)나 장비들이 사용되는데, 이러한 장비들은 크기가 작고 가벼워 이동하기 용이하고, 사용법도 간편하
Received Jul 17, 2020 Revised Jul 29, 2020

Accepted Jul 30, 2020

Corresponding author Seol Park

E-mail parksul85@hanmail.net
Copylight (C)2020 The Korean Society of Physical Therapy

This is an Open Access article distribute under the terms of the Creative Commons Attribution Non-commercial License (https:// creativecommons.org/license/by-nc/4.0.) which permits unrestricted non-commercial use, distribution, and reproduction in any medium, provided the original work is properly cited. 
므로 임상이나 가정에서 많이 사용되고 있다. 하지만 휴대성이 좋은 진동 장비를 사용하여 $\mathrm{LV}$ 를 적용한 연구는 드물며, 스트레칭과 같이 유연성 향상을 위한 전통적인 중재 방법과의 비교도 충분히 이루어 지지 않았다.

따라서 본 연구에서는 시중에 많이 판매되고 있는 휴대용 LV 장비 를 사용하여 종아리세갈래근(triceps surae)에 적용했을 때 발목관절 발등굽힘(dorsiflexion, $\mathrm{DF}$ ) 관절가동범위(range of motion, $\mathrm{ROM}$ )를 측 정하여 종아리세갈래근의 유연성 향상에 미치는 효과를 알아보고 자 하였으며, 이를 정적 스트레칭(static stretching, SS)과 비교하였다.

\section{연구 방법}

\section{1. 연구대상}

본 연구에서는 20 명의 피험자를 대상으로 하였으며, 실험 전 본 연구 의 목적 및 위험성에 대해 충분히 설명한 후 본 실험에 대해 동의한 자로 하였다. 또한 보행이나 균형에 문제가 없는 자, 최근 6개월 이내 에 하지 관절의 정형외과적, 신경외과적 수술이나 부상의 경험이 없 는 자, 실험 당시 종아리세갈래근에 대한 치료를 받지 않은 자로 구성 되었다. 실험 전 피험자들의 나이, 키, 몸무게, 그리고 우세측 다리를 측정하였다. 우세측 다리는 공을 찰 때 사용하는 발로 정하였다 $(\mathrm{Ta}-$ ble 1).

\section{2. 실험방법}

1) $\mathrm{ROM}$ 측정

실험 전 피험자들은 바로 누운 자세에서 $\mathrm{DF} \mathrm{ROM}$ 을 측정하였고 이 를 열린 사슬에서 측정한 ROM 값으로 사용하였다. 이후 바로 선 자 세에서 체중 부하 런지 검사(weight-bearing lunge test)를 실시하여 닫 힌 사슬에서의 DF ROM을 측정하였다. 체중 부하 런지 검사는 신뢰 도가 검증되어 있으며, ${ }^{14,15}$ 바로 선 자세에서 실험측 다리의 무릎을 편 상태로 발뒤꿈치가 땅에서 떨어지기 직전까지 비실험측 다리를 앞으 로 내미는 동작으로 수행되며, 발이 땅에서 떨어지기 직전의 DF $\mathrm{ROM}$ 값을 측정하였다. ROM은 각도계(Jamar, USA)를 사용하였으며, 열린 사슬과 닫힌 사슬에 따라 움직팔과 고정팔을 정하였다. 열린 사

Table 1. General characteristics of subjects

\begin{tabular}{lccc}
\hline & LV & SS & p \\
\hline $\mathrm{N}(\mathrm{M}: \mathrm{F})$ & $10(4: 6)$ & $10(5: 5)$ & \\
Age (yr) & $26.7 \pm 8.26$ & $23.2 \pm 3.05$ & 0.23 \\
Height (cm) & $168.8 \pm 9.82$ & $172.2 \pm 12.51$ & 0.51 \\
Weight (kg) & $68.9 \pm 16.5$ & $75.6 \pm 14.43$ & 0.35 \\
Dominant (R:L) & $10: 00$ & $10: 00$ & \\
\hline
\end{tabular}

LV: Local vibration group, SS: Static stretching group.
슬에서의 움직팔과 닫힌 사슬에서의 고정팔은 다섯번째 발허리뼈 $\left(5^{\text {th }}\right.$ metatarsal $)$ 와 일치시켰으며, 열린 사슬에서의 고정팔과 닫힌 사슬 에서의 움직팔은 종아리뼈머리(fibular head)와 가쪽복사뼈(lateral malleolus)를 이은 가상의 선과 일치시켰다. DF ROM 0 는 발목관절이 $90^{\circ}$ 를 이루었을 때로 설정하였다. 모든 값은 두 번 측정 후 평균값을 사용하으며, 모든 검사 시 우세측 다리를 측정하였다. 모든 중재 후 $\mathrm{DF} \mathrm{ROM}$ 을 재측정하였다. 중재 전과 후에 $\mathrm{DF} \mathrm{ROM}$ 을 측정하였으며, 중재 후의 $\mathrm{ROM}$ 에서 중재 전 $\mathrm{ROM}$ 을 뺀 값으로 ROM의 변화량을 계 산하였다.

\section{2) 중재 방법}

\section{(1) 국소 진동 $(\mathrm{LV})$}

본 연구에서 사용한장비는 Yunmai (YUNMAI technology Co., China) 마사지 건으로, $10 \mathrm{~mm}$ 의 진폭으로 1 분에 1,800 회에서 3,200 회까지 3 단계의 속도로 진동을 제공한다. 본 연구에서는 가장 느린 속도인 $1800 \mathrm{rpm}$ 으로 적용하였다. 마사지 건의 헤드 부분은 EVA 재질로 되 어 있으며 모양에 따라 4가지 종류로 구성되어 있는데, 본 연구에서 는 가장 좁은 면을 가진 헤드를 선택하였다. 마사지 건의 총 무게는 $0.8 \mathrm{~kg}$ 이다(Figure 1).

$\mathrm{LV}$ 그룹의 피험자들은 엎드려 누운 자세에서 종아리세갈래근 부위에 마사지 건을 사용하여 $\mathrm{LV}$ 를 적용하였다. 이때 장딴지근 등 종아리세갈 래근의 근섬유 방향을 따라 적용하였으며, 통증이나 불편감을 느끼는 부위에 좀 더 집중하여 적용하였다. 총 적용 시간은 약 5 분으로, 한 회 당 1 분 적용 후 30 초 휴식을 취하도록 하여 총 3 회 실시하였다.

\section{(2) 정적 스트레칭(SS)}

정적 스트레칭 그룹은 삼각형 모양의 웨지(Q-board, Uhan Medical, Korea) 위에 서서 발목을 발등굽힘 한 채로 5 분간 서 있도록 하였다.

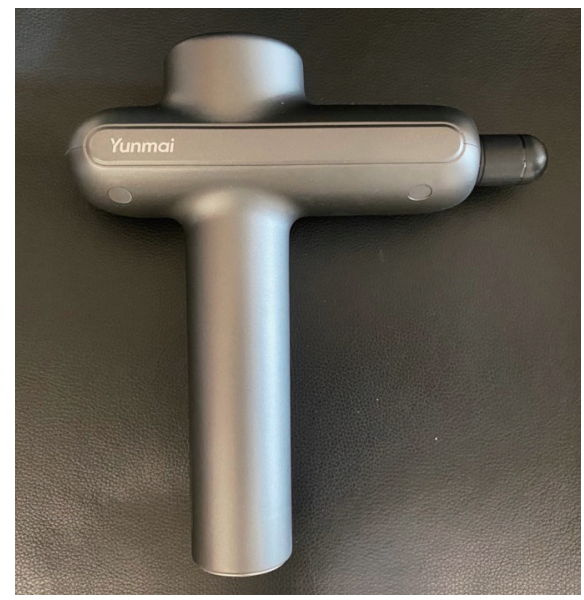

Figure 1. The massage gun used in this study. 
본 실험에서 사용한 웨지는 시중에서 쉽게 찾아볼 수 있는 것으로, $\mathrm{DF} \mathrm{ROM} \mathrm{증가를} \mathrm{위해} \mathrm{임상이나} \mathrm{가정에서} \mathrm{많이} \mathrm{쓰이고} \mathrm{있다.} \mathrm{웨지의}$ 높이는 모든 피험자들이 약간의 불편함을 느끼는 정도인 $160 \mathrm{~mm}$ 로 적용하였다. 피험자는 발을 DF 시킨 상태로 양 발로 웨지 위에 서 있 도록 하였으며, 넘어짐을 방지하기 위해 벽을 짚고 서 있도록 하였다. 1 분 적용 후 30 초 휴식을 취하도록 하였으며 총 적용 시간은 약 5 분이 었다.

\section{3. 자료 수집 및 분석}

피험자의 일반적인 특성을 알아보기 위해 기술 통계를 실시하였으며, Levene's test를 통해 집단 간 분산의 동질성을 검사하였다 $(\mathrm{p}>0.05)$. 또 한 정규성 검정을 위해 Shapiro-Wilk test를 실시하였으며, 모두 만족 하여 $(\mathrm{p}>0.05)$ 각 중재의 효과를 검증하였다. 그룹 내에 중재 전후 차 이를 알아보기 위해 paired t-test를 실시하였고, 그룹 간 ROM의 변화 량 차이를 알아보기 위해 independent t-test를 실시하였다. 통계는 윈 도우용 SPSS version 20 을 이용하였으며, 유의 수준은 $\alpha=0.05$ 로 설정 하였다.

Table 2. Comparison of ankle dorsiflexion range of motion between pre-and post-intervention and groups

(mean \pm SD)

\begin{tabular}{llccc}
\hline Position & & $\mathrm{LV}\left(^{\circ}\right)$ & $\mathrm{SS}\left(^{\circ}\right)$ & $\mathrm{p}$ \\
\hline OKC & Pre & $14.6 \pm 3.78$ & $12.9 \pm 4.65$ & 0.382 \\
& Post & $19.4 \pm 6.79$ & $15.4 \pm 3.69$ & 0.119 \\
& Change & $4.8 \pm 4.34$ & $2.5 \pm 1.78$ & 0.138 \\
& $\mathrm{p}$ & $0.007^{+}$ & $0.002^{+}$ & \\
CKC & Pre & $15.9 \pm 3.38$ & $15.1 \pm 3.78$ & 0.624 \\
& Post & $20.1 \pm 6.94$ & $18.6 \pm 4.38$ & 0.57 \\
& Change & $4.2 \pm 4.47$ & $3.5 \pm 2.55$ & 0.672 \\
& p & $0.016^{*}$ & $0.002^{+}$ &
\end{tabular}

${ }^{*} p<0.05,{ }^{+} p<0.01$. LV: Local vibration group. SS: Static stretching group, OKC: Open kinetic chain measured in supine position, CKC: Closed kinetic chain measured in standing.

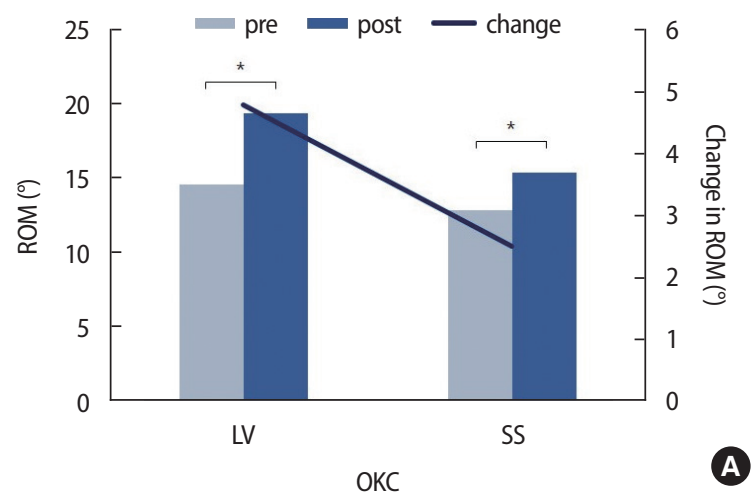

결 과

\section{1. 그룹 내 중재 전후의 DF ROM 비교}

중재 전후의 DF ROM을 비교한 결과 두 그룹 모두 열린 사슬 자세와 닫힌 사슬 자세에서 유의한 차이가 있었다( $\mathrm{p}<0.05)($ Table 2, Figure 2).

\section{2. 그룹 간 ROM 변화량 비교}

중재 전후의 차이 값인 DF ROM의 변화량을 비교해 본 결과 열린 사 슬 $(\mathrm{p}=0.138)$ 과 닫힌 사슬 $(\mathrm{p}=0.672)$ 모두에서 두 그룹 사이에 유의한 차이가 없었다(Table 2, Figure 2)

\section{고 찰}

본 연구는 마사지 건으로 적용한 LV가 종아리근육의 유연성에 미치 는 효과를 알아보기 위해 5 분간 종아리세갈래근에 $\mathrm{LV}$ 를 적용한 후 $\mathrm{DF} \mathrm{ROM}$ 을 측정하였으며, 그 값을 SS와 비교하였다. 그 결과 두 중재 모두 ROM 증가에 효과가 있었지만, 두 그룹 사이에 차이는 없었다.

진동을 적용한 중재에 대한 효과는 근력 강화, ${ }^{2,17}$ 유연성 향상,-3 통 증 감소 ${ }^{4}$ 등으로, 임상에서 많이 활용되고 있다. 그 중 $\mathrm{LV}$ 는 국소 부위 에 진동을 주는 방식으로, 근육에 적용할 경우 유연성을 향상시키고 경직을 감소시킨다.6.13 국소 부위에 적용하는 진동은 근육이나 힘줄 에 주로 적용하며, 진동 자극이 근방추나 골지힘줄기관을 자극하여 통증 역치를 변화시키고 ${ }^{5}$ 근수축 단위의 발화율과 동원 역치를 조정 함으로써16 유연성 증가와 통증 감소의 효과를 준다. 선행 연구에서 는 경직, ${ }^{4}$ 허리통증, ${ }^{4}$ 발목 뻼, ${ }^{13}$ 뒤넙다리근 긴장, ${ }^{13}$ 뼈관절염17 등 다양 한 피험자를 대상으로 $\mathrm{LV}$ 가 유연성이나 경직 정도, ${ }^{6,13,17}$ 근력, ${ }^{18}$ 보행능 력과 같은 기능 ${ }^{17}$ 에 미치는 영향을 연구하였고, 그 결과 광범위한 질 환과 대상에 효과를 보이는 것으로 나타났다. 본 실험에서는 DF $\mathrm{ROM}$ 을 측정하여 종아리세갈래근의 유연성을 알아보았으며, 그 결

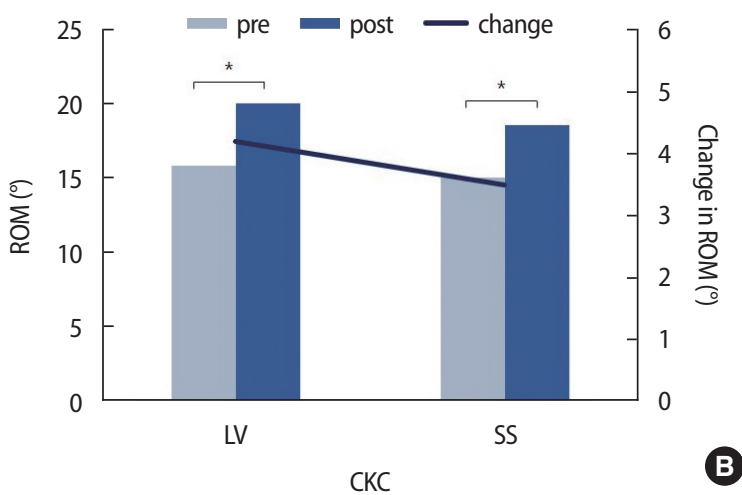

Figure 2. Dorsiflexion range of motion between pre-and post-intervention and groups. * Significantly different between pre-and post-intervention. LV: Local vibration group, SS: Static stretching group, OKC: Open kinetic chain measured in supine, CKC: Closed kinetic chain measured in standing. 
과 $\mathrm{LV}$ 적용이 $\mathrm{DF} \mathrm{ROM}$ 을 증가시킨 것으로 나타나 선행 연구와 일치 했다.

$\mathrm{LV}$ 를 적용하는 방법은 Theragun 이나 YUNMAI 마사지 건과 같은 휴대용 근육타진기(hand held percussion device)를 이용하는 것이 휴 대성이 좋고 사용하기 쉬우며 경제적인 이득이 있다. 마사지 건의 경 우 시판되고 있는 제품이 많으며 가격이 저렴한 편이라 임상에서뿐 만 아니라 가정에서도 많이 사용된다. 임상가들에게는 현장에서 환 자나 운동선수들을 대상으로 할 경우 휴대용 마사지 건을 쉽게 적용 할 수 있어 유리하다. 본 연구에서는 마사지 건을 사용한 LV가 유연 성 향상에 효과가 있음을 증명하였으므로, 향후 $\mathrm{LV}$ 적용이 필요한 대상자를 대상으로 언제 어디서든 휴대성이 좋은 마사지 건을 이용 해 쉽고 편하게 적용할 수 있음을 제안한다.

$\mathrm{WBV}$ 가 근력 강화에 효과가 있는 것과는 달리 $\mathrm{LV}$ 는 유연성 향상 에 효과가 있는데, 이는 WBV의 경우 진동판 위에서 주로 스쿼트 등 기존의 다른 운동을 하는 동시에 진동을 적용한 효과를 보았으므로, 기존의 운동만을 시행했을 때보다 근력 강화나 균형, 기능에 더 효과 가 있었다는 것을 증명한 연구들이 대부분이었던 반면, ${ }^{8-11} \mathrm{LV}$ 의 경우 특정한 근육이나 힘줄에 적용하여 근육의 유연성이나 경직 정도를 개선하는 연구가 진행되었기 때문이다. Goebel 등 ${ }^{18}$ 은 저항 훈련을 하 는 동안 뒤넙다리근에 $\mathrm{LV}$ 를 적용하였고, 이를 $\mathrm{LV}$ 를 적용하지 않은 대 조군과 비교한 결과 두 그룹 모두에서 등척성 근력이 증가하였다. 하 지만 무릎관절의 최대 $\mathrm{ROM}$ 또한 증가하였으며 대조군보다 뒤넙다 리근의 긴장이 덜 증가하였으므로 $\mathrm{LV}$ 가 최대 등척성 근력을 증가시 키는 데에도 일반적인 저항훈련보다 더 효과적이라고 하였다. 이와는 반대로 Kujala 등 ${ }^{19}$ 은 $\mathrm{LV}$ 의 적용이 수직 점프 높이에 영향을 미치지 않았다고 보고하였으므로, $\mathrm{LV}$ 가 근력 강화에 미치는 효과는 더 연구 되어야할 필요가 있다.

$\mathrm{WBV}$ 와 $\mathrm{LV}$ 를 비교한 Kurt 등ㄹㅇㅢ 연구에서는 하지 근육에 적용한 $\mathrm{LV}$ 가 $\mathrm{WBV}$ 와 동적 스트레칭보다 서서 팔 뻗기 검사(stand and reach test)에서 더 큰 효과가 있었음을 보고하였다. 흥미로운 점은 정적 스 트레칭의 경우 $\mathrm{LV}$ 와 유의한 차이가 없었다는 점이다. 이는 본 연구의 결과와 일치하는 것으로, 본 연구에서도 SS 적용 전후의 ROM 변화 값이 $\mathrm{LV}$ 의 값과 유의한차이가 없었으므로, 두 중재의 효과가 같다고 볼 수 있다. ROM을 증가시키기 위한 중재 방법은 다양하지만,20-23 그 중 SS는 근육의 유연성을 향상시키는 데 효과적이며, 가장 주된 방법 으로 쉽게 적용할 수 있을 뿐만 아니라 효과가 빠르다. ${ }^{24}$ 따라서 운동 이나스포츠 경기 전 워밍업을 위한 루틴으로 쓰이고 있다. 본 연구에 서는 가장 전통적인 스트레칭 방법인 SS를 대조군으로 설정하여 $\mathrm{LV}$ 의 효과를 검증하고자 하였으며, $\mathrm{LV}$ 의 적용이 SS의 효과만큼 이득을 볼 수 있음을 알 수 있었다. 하지만 휴대성과 편익성이 좋은 마사지 건 을 사용할 경우 종아리세갈래근 뿐만 아니라 유연성이 필요한 신체
어느 부위에도 쉽게 적용할 수 있는 이점이 있으며, 추가적으로 혈류 순환 향상 및 열 효과, ${ }^{6}$ 심혈관 확장으로 인한 근육의 신장력 촉진 및

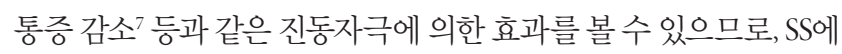
비해 LV가 더 효용성이 있다고 할 수 있다.

본 연구의 제한점은 피험자의 수가 적었다는 점이며, 남녀 간 스트 레칭에 대한 반응이 다르므로 ${ }^{25}$ 성별에 따른 차이를 알아볼 필요가 있다. 각 중재를 5 분간 적용하였으므로 $\mathrm{LV}$ 의 즉각적인 $\mathrm{ROM}$ 개선 효 과로 봐야 한다는 점, 사후 검증을 실시하지 않아 ROM 개선 효과의 지속성을 알아보지 않았다는 점 또한 제한점이다. 향후 연구에서는 $\mathrm{LV}$ 의 지속성에 대한 연구와, 적절한 중재 시간, 빈도, 주파수, 헤드 유 형 등을 알아볼 수 있도록 함으로써 LV 적용에 대한 프로토콜을 제 시할수 있어야할 것이다.

본 연구에서는 $\mathrm{LV}$ 가 종아리세갈래근의 유연성에 미치는 효과를 알아보기 위하여 중재 전후 DF ROM을 비교하였으며, 5 분간의 LV 적 용이 종아리세갈래근의 유연성을 향상시키는 데에 효과가 있음을 알 수 있었다. 또한 SS와의 비교를 통해 LV가 SS 만큼의 효과가 있음 을 알 수 있었다. 향후 임상가들에게 LV 적용이 필요한 대상자를 대 상으로 언제 어디서든 휴대성이 좋은 마사지 건을 이용해 쉽고 편하 게 적용할 수 있음을 제안한다.

\section{REFERENCES}

1. Fanani F, Giombini A, Di Cesare A et al. The effects of a whole-body vibration program on muscle performance and flexibility in female athletes. Am J Phys Med Rehabil. 2006;85(12):956-62.

2. Jacobs PL, Burns P. Acute enhancement of lower-extremity dynamic strength and flexibility with whole-body vibration. J Strength Cond Res. 2009;23(1):51-7.

3. Kinser AM, Ramsey MW, O'Bryant HS et al. Vibration and stretching effects on flexibility and explosive strength in young gymnasts. Med Sci Sports Exerc. 2008;40(1):133-40.

4. Patel R, Patel A. Effect of theragun on the improvement of back flexibility: A case study. J Appl Dent Med Sci. 2020;19(5):15-6.

5. Ribot-Ciscar E, Rossi-Durand C, Roll JP. Muscle spindle activity following muscle tendon vibration in man. Neurosci Lett. 1998;2585(3):14750 .

6. Bakhtiary AH, Fatemi E, Khalili MA et al. Localised application of vibration improves passive knee extension in women with apparent reduced hamstring extensibility: A randomized trial. J Physiother. 2011;57(3): 165-71.

7. Oliveri DJ, Lynn K, Hong CZ. Increased skin temperature after vibratory stimulation. Am J Phys Med Rehabil. 1989;68(2):81-5.

8. Costantino C, Bertuletti S, Romiti D. Efficacy of whole-body vibration board training on strength in athletes after anterior cruciate ligament reconstruction: A randomized controlled study. Clin J Sport Med. 2018; 28(4):339-49.

9. Seixas A, Sañudo B, Sá-Caputo D et al. Whole-body vibration for indi- 
viduals with reconstructed anterior cruciate ligament: A systematic review. Biomed Res Int. 2020;2020;7362069

10. Sierra-Guzman R, Jimenez-Diaz F, Ramirez C et al. Whole-body-vibration training and balance in recreational athletes with chronic ankle instability. J Athl Train. 2018;53(4):355-63.

11. Saquetto M, Carvalho V, Silva C et al. The effects of whole body vibration on mobility and balance in children with cerebral palsy: A systematic review with meta-analysis. J Musculoskeletal Neuronal Interact. 2015;15(2):137-44.

12. Kurt C. Alternative to traditional stretching methods for flexibility enhancement in well-trained combat athletes: Local vibration versus whole-body vibration. Biol Sport. 2015;32(3):225-33.

13. Peer KS, Barkley JE, Knapp DM. The acute effects of local vibration therapy on ankle sprain and hamstring strain injuries. Phys Sportsmed. 2009;37(4):31-8.

14. Chisholm MD, Birmingham TB, Brown J et al. Reliability and validity of a weight-bearing measure of ankle dorsiflexion range of motion. Physiother Can. 2012;64(4):347-55.

15. Park JW, Park S. Inter-rater reliability of cervical proprioception, dynamic balance and dorsiflexion range of motion using STARmat. J Kor Phys Ther. 2020;32(2):88-93.

16. Issurin VB. Vibrations and their applications in sport. A review. J Sports Med Phys Fitness. 2005;45(3):324-36.

17. Benedetti MG, Boccia G, Cavazzuti L et al. Localized muscle vibration reverses quadriceps muscle hypotrophy and improves physical function: A clinical and electrophysiological study. Int J Rehabil Res. 2017;40
(4):339-46

18. Goebel RT, Kleinoder H, Yue Z et al. Effect of segment-body vibration on strength parameters. Sports Med Open. 2015;1(1):14.

19. Kujala R, Davis C, Young L. The effect of handheld percussion treatment on vertical jump height. Int J Exerc Sci: Conference Proceedings. 2019;8 (7):75.

20. Jeon HM. The effects of interventions that increase the ankle dorsi-flexion on muscle contraction and dynamic balance. Catholic University of Daegu. Dissertation of Master's Degree. 2019.

21. Kang TW, Kim BR. The effects of stretching and strengthening exercise on the pain, pelvic tilt, functional disability index, and balance ability of patients with chronic lower back pain. J Kor Phys Ther. 2019;31(1):7-12.

22. Kim KS, Jeon IC. Effectiveness of iliopsoas self-stretching on hip extension angle, gluteus maximus activity, and pelvic compensations during prone hip extension in subjects with iliopsoas shortness. J Kor Phys Ther. 2018;30(1):23-8.

23. Lee JH, Kim JY, Kim HS et al. Comparison of sit and reach test, straight leg raise test and visual analogue scale when applying static stretching and mulligan's two leg rotation in young adults with hamstring shortness. J Kor Phys Ther. 2019;31(5):266-72.

24. Skarabot J, Beardsley C, Stirn I. Comparing the effects of self-myofascial release with static stretching on ankle range-of-motion in adolescent athletes. Int J Sports Phys Ther. 2015;10(2):203-12.

25. Gajdosik RL. Relation of age and passive properties of an ankle dorsiflexion stretch to the timed one-leg stance test in older women. Percept Mot Skills. 2006;103(1):177-82. 